\title{
Charcoal Disrupts Soil Microbial Communication through a Combination of Signal Sorption and Hydrolysis
}

\author{
Xiaodong Gao, ${ }^{\dagger, \perp}$ Hsiao-Ying Cheng, ${ }^{\ddagger, \perp}$ Ilenne Del Valle, ${ }^{\S}$ Shirley Liu, ${ }^{\prime}$ Caroline A. Masiello, ${ }^{\dagger, \|}$ \\ and Jonathan J. Silberg*,*,\|
}

${ }^{\dagger}$ Department of Earth Science, ${ }^{\ddagger}$ Department of Bioengineering, ${ }^{\S}$ Systems, Synthetic, and Physical Biology Graduate Program, and
${ }^{\|}$Department of Biosciences, Rice University, 6100 Main Street, Houston, Texas 77005 , United States

Supporting Information

ABSTRACT: The presence of charcoal in soil triggers a range of biological effects that are not yet predictable, in part because it interferes with the functioning of chemical signals that microbes release into their environment to communicate. We do not fully understand the mechanisms by which charcoal alters the biologically available concentrations of these intercellular signals. Recently, charcoal has been shown to sorb the signaling molecules that microbes release, rendering them ineffective for intercellular communication. Here, we investigate a second, potentially more important mechanism of interference: signaling-molecule hydrolysis driven by charcoal-induced soil $\mathrm{pH}$ changes. We examined the effects of 10 charcoals on the bioavailable concentration of an acyl-homoserine lactone (AHL) used by many Gram-negative bacteria for cell-cell communication. We show that charcoals decrease the level of bioavailable $\mathrm{AHL}$ through sorption and $\mathrm{pH}$-dependent hydrolysis of the lactone ring. We then built a quantitative model that predicts the half-lives of different microbial signaling compounds in the presence of charcoals varying in $\mathrm{pH}$ and surface area. Our
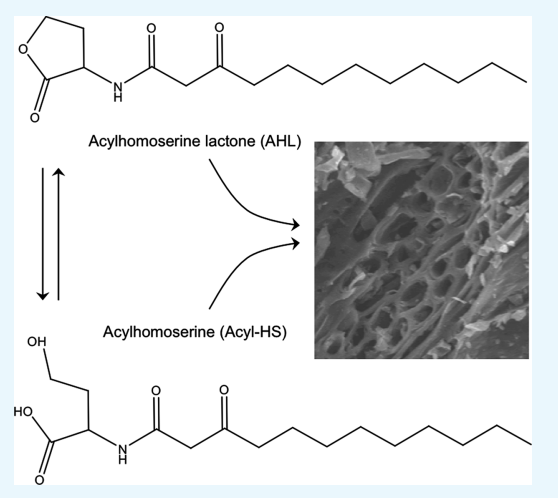
model results suggest that the chemical effects of charcoal on $\mathrm{pH}$-sensitive bacterial AHL signals will be fundamentally distinct from effects on $\mathrm{pH}$-insensitive fungal signals, potentially leading to shifts in microbial community structures.

\section{INTRODUCTION}

Charcoal intentionally added to soil (called biochar) can trigger a wide range of biological effects such as changing microbial community structure, ${ }^{1,2}$ soil nitrogen cycling, ${ }^{3,4}$ and plant-microbe symbiosis. ${ }^{5,6}$ Charcoal has also been shown to alter the rate at which microbes decompose soil organic carbon, ${ }^{7-9}$ inducing both increases and decreases in soil organic carbon mineralization. Interference with microbial cell-cell signaling (e.g., quorum sensing) is likely to be one of the mechanisms driving charcoal-induced microbial responses. ${ }^{10,11}$ In quorum sensing, microbes regulate physiological activities based on their population density. ${ }^{12}$ To sense the population density, microbes synthesize chemical signals (called autoinducers) that diffuse across cell membranes and use the accumulation of these molecules to activate receptors that control gene expression. $^{12}$ Early studies of quorum sensing linked this community-level decision making to bioluminescence, biofilm formation, virulence, plasmid transfer, and antibiotic synthesis. $^{12}$ Increasing evidence points to the role of quorum sensing in the regulation of key processes in the biogeochemical cycling of carbon and nitrogen such as development of the microbe-plant symbioses critical for nitrogen fixation, ${ }^{13}$ secretion of enzymes that destabilize soil organic matter, ${ }^{14}$ and production of methane by some archaea. ${ }^{15}$ Cell-cell signaling has also been shown to regulate the growth of ammonia-oxidizing bacteria and the production of $\mathrm{N}_{2} \mathrm{O}$ after starvation, $^{16}$ and it has been shown to downregulate denitrification. ${ }^{17,18}$ Although charcoal has been proposed to alter microbial behaviors by interfering with quorum sensing, ${ }^{11}$ our fundamental understanding of the chemical reactivity of charcoal with signaling molecules remains too limited to predict how the physicochemical properties of a given charcoal will impact signaling within a single microbial species or how charcoal will differentially affect bacteria and fungi that use distinct chemical signals for communication.

The processes that decrease the concentration of intercellular signaling molecules increase the population density required to trigger signal-dependent behaviors, such as $\mathrm{N}_{2} \mathrm{O}$ production, $\mathrm{N}$ fixation, or production of some enzymes that decompose soil organic carbon. ${ }^{13,16-18}$ The concentration of signaling molecules can be diminished ("quenched") by enzymatic degradation, ${ }^{19}$ sorption to abiotic materials, ${ }^{20}$ abiotic degradation reactions, $^{21,22}$ and interference by other chemicals. ${ }^{23}$ Charcoal has recently been proposed to contribute to the quenching of cell-cell communication in the environment, ${ }^{5,24}$ displaying quenching activities that correlate with amendment amounts and production conditions. ${ }^{11}$ The strong sorptive affinity that charcoal has for apolar organic compounds ${ }^{25-28}$ suggests that it will efficiently sorb the diverse types of apolar signaling molecules synthesized by archaea, bacteria, fungi, and plants.

Received: June 20, 2016

Accepted: August 8, 2016

Published: August 23, 2016 
Indeed, recent work demonstrated that charcoal disrupts the cell-cell signaling mediated by $\mathrm{N}$-3-oxo-dodecanoyl-L-homoserine lactone, ${ }^{11}$ an AHL intercellular signaling molecule used by many Gram-negative soil bacteria to regulate gene expression. In that study, charcoal quenching of cell-cell communication correlated with the charcoal surface area (SA), which also covaried with the charcoal production temperature. $^{11}$

Although previous work showed a role for SA in charcoal quenching of quorum sensing, charcoal has many physicochemical properties that can vary with pyrolysis temperature and feedstock, including alkalinity, aromaticity, density, hydrophobicity, and porosity. ${ }^{29-32}$ We hypothesized that, among these properties, alkalinity would also influence microbial quorum sensing because some autoinducers have structures that are sensitive to elevated $\mathrm{pH}^{22}$ In the case of AHLs, alkalinity causes hydrolysis of the lactone ring, yielding an acylhomoserine (Acyl-HS) product that can be inactive for cellcell signaling. ${ }^{21,22}$ This susceptibility to hydrolysis at elevated $\mathrm{pH}$ suggests that the alkalinity of some charcoals may decrease AHL levels, perhaps even more efficiently than surface sorption. The effects of charcoal on AHL hydrolysis kinetics are expected to vary, because ash produced during pyrolysis can lead to a wide range of charcoal $\mathrm{pH}$ values (at least $5-10) .{ }^{33}$ The extent to which alkalinity contributes to the charcoal quenching of AHL signaling has not been evaluated, and it is unclear how the rates of AHL inactivation through sorption and hydrolysis relate to one another.

The objective of this study was to determine the effect of charcoal alkalinity on microbial AHL signaling. We compared the effects of 10 charcoals on AHL stability and used our results to build a model that explores how charcoals with different SAs and $\mathrm{pH}$ values will affect the half-life of an AHL signaling molecule. We used N-3-oxo-dodecanoyl-L-homoserine lactone as a representative AHL because charcoal is known to influence the bioavailable levels of this signaling molecule. ${ }^{11} \mathrm{We}$ provide evidence that the rate of AHL quenching varies by more than a factor of $10^{4}$ over a range of $\mathrm{pH}$ and $\mathrm{SA}$ values found in charcoals created from five different feedstocks. Our model also allowed us to compare the relative effects of different charcoals on an AHL with their effects on a representative fungal signaling molecule, farnesol.

\section{MATERIALS AND METHODS}

Materials. Escherichia coli XL1-Blue was purchased from Stratagene, AHL (N-3-oxo-dodecanoyl-L-homoserine, N-3-oxoC12 HSL) was purchased from Cayman Chemical, and all other reagents were from Sigma-Aldrich, VWR, or BD Biosciences. The Luria-Bertani (LB) growth medium contained $100 \mathrm{mM}$ 3-(N-morpholino) propanesulfonic acid (MOPS) $\mathrm{pH}$ 7. MOPS was included to buffer the growth medium against $\mathrm{pH}$ changes arising from reaction with the charcoal-treated solutions.

Charcoal Production. Charcoals prepared from oilseed rape, wheat straw, miscanthus straw, mixed softwood, and rice husk feedstocks were obtained from the UK Biochar Research Center (UKBRC, University of Edinburgh, UK). Each feedstock was subjected to slow pyrolysis at 550 and $700{ }^{\circ} \mathrm{C}$ under $\mathrm{N}_{2}$ in a pilot-scale pyrolysis unit with a continuous-feed rotary kiln. All feedstock materials were pelletized to a size of 5 $\times 20 \mathrm{~mm}$ before pyrolysis except for the rice husk. The charcoals were gently crushed by mortar and pestle and sieved to obtain charcoals of size $<1.4 \mathrm{~mm}$.
Charcoal Characterization. The samples were degassed in glass cells, vacuum-dried overnight at $200{ }^{\circ} \mathrm{C}$, and analyzed using a Quantachrome Autosorb-3b Surface Analyzer. $\mathrm{N}_{2}$ adsorption/desorption isotherms were obtained at $77 \mathrm{~K}$ by a 26-point analysis for relative pressures $P / P_{0}$ ranging from 1.21 $\times 10^{-4}$ to 0.99 , where $P$ is the adsorption equilibrium pressure and $P_{0}$ is the vapor pressure of bulk liquid $\mathrm{N}_{2}$. Specific SA was calculated using Brunauer-Emmett-Teller (BET) theory as previously described. ${ }^{11}$ Charcoal $\mathrm{pH}$ was measured using a 1:20 charcoal/water mixture $(\mathrm{w} / \mathrm{w})$ after a $1.5 \mathrm{~h}$ reaction while shaking. The UKBRC charcoals exhibited a large variation in SA (1.9-145.0 $\mathrm{m}^{2} \mathrm{~g}^{-1}$ ) and $\mathrm{pH}(7.88-10.69)$ (Figure S1). Those with the highest SA (softwood) displayed the lowest $\mathrm{pH}$, whereas those with the lowest SA (oilseed rape) exhibited high $\mathrm{pH}$.

Microbial Assay. Physiologically and environmentally relevant AHL concentrations are on the order of $100 \times$ lower than the detection limit of commonly available forms of analytical instrumentation, for example, gas chromatographymass spectrometry (GC-MS). ${ }^{34}$ We therefore used a microbial biosensor to detect the presence of biologically active AHL, using an approach previously described by our group. ${ }^{11}$ This biosensor has a detection threshold of $100 \mathrm{pM}$, whereas the detection threshold of GC-MS was $\sim 5 \mu \mathrm{M}$, similar to previous studies. ${ }^{35}$ We added varying concentrations of the UKBRC charcoals $(0,1,5,10,25$, and $50 \mathrm{mg} / \mathrm{mL})$ to water containing 2 $\mu \mathrm{M}$ AHL for $60 \mathrm{~min}$ at $23{ }^{\circ} \mathrm{C}$ while shaking at $100 \mathrm{rpm}$. The charcoal was removed through centrifugation $(13000 \mathrm{~g}, 1 \mathrm{~min})$, the $\mathrm{pH}$ of the supernatant fraction was analyzed using a micro $\mathrm{pH}$ electrode, and aliquots of the supernatant were mixed in a 96-well plate (Corning Costar) with identical volumes of LBMOPS containing E. coli (at an $\mathrm{OD}_{600}=0.05$ ) transformed with the receiver plasmid and $50 \mu \mathrm{g} / \mathrm{mL}$ kanamycin. The receiver plasmid encoded a green fluorescent protein (GFP) that is expressed only in the presence of AHL. ${ }^{11}$ Cells were incubated at $30{ }^{\circ} \mathrm{C}$ while shaking at $250 \mathrm{rpm}$ for $18 \mathrm{~h}$; whole cell fluorescence $\left(\lambda_{\mathrm{ex}}=488 ; \lambda_{\mathrm{em}}=509\right)$ and absorbance $(600 \mathrm{~nm})$ were measured using a Tecan M1000 plate reader. This long incubation was used to ensure that our assay was able to report on low levels of AHL remaining in solution after charcoal incubations. In all experiments, cultures grew to a similar maximal density as observed previously when this biosensor was used to study the effects of charcoal on AHL bioavailability. ${ }^{11}$ To account for well-to-well variation in cell density, fluorescence was normalized to absorbance. Data were reported as a fraction of the signal obtained with AHL that had not been incubated with charcoal (Figure S2). All data represent the average of three or more independent incubation experiments. For each incubation, three replicate measurements were performed in parallel.

Acidified Charcoal. We arrayed $550{ }^{\circ} \mathrm{C}$ miscanthus straw charcoal in 24-well plates in $2 \mathrm{~mL}$ of sterile water at different concentrations $(0,1,5,10,25$, and $50 \mathrm{mg} / \mathrm{mL})$. Each well was acidified with $\mathrm{HCl}$ to $\mathrm{pH} 3$ and shaken at $100 \mathrm{rpm}$ overnight at $23{ }^{\circ} \mathrm{C}$. Depending on the charcoal concentration, different $\mathrm{HCl}$ concentrations were used to minimize changes in the liquid volume. The $\mathrm{pH}$ was measured a second time, and the samples were acidified again to $\mathrm{pH} 3$ using $\mathrm{HCl}$. AHL was then added to each sample at a concentration of $2 \mu \mathrm{M}$ and held at $23^{\circ} \mathrm{C}$ for $60 \mathrm{~min}$ while shaking. At the end of these reactions, we measured the concentration of soluble AHL and solution $\mathrm{pH}$ as described above. 
AHL Hydrolysis Kinetics. To develop a model that predicts the rates of lactone hydrolysis in the presence of charcoals having a range of $\mathrm{pH}$ and SA properties, we needed to measure AHL hydrolysis kinetic parameters so that we could constrain our model. We measured the $\mathrm{pH}$-dependent hydrolysis of AHL using GC-MS, which necessitated the use of a high AHL concentration $(0.05 \mathrm{mM})$. Hydrolysis rates were determined at $25{ }^{\circ} \mathrm{C}$ by adjusting solutions containing $\mathrm{AHL}$ concentrations suitable for GC-MS analyses to different $\mathrm{pH}$ values $(6.7,8.1,9.6$, and 10.5) using $0.1 \mathrm{~N} \mathrm{NaOH}$. At different times after $\mathrm{pH}$ adjustment ( $1 \mathrm{~min}, 15 \mathrm{~min}, 1 \mathrm{~h}, 2 \mathrm{~h}$, and $24 \mathrm{~h}$ ), each sample was split into two fractions. One fraction was mixed with an equal volume of chloroform to extract the soluble AHL, and the concentration of AHL ([AHL $\left.]_{\text {soluble }}\right)$ was analyzed using GC-MS. The other fraction was acidified to $\mathrm{pH}$ 3 using $\mathrm{HCl}$, shaken for 15 min to convert Acyl-HS that formed during the reaction into AHL, and analyzed for AHL content using GC-MS. This 15 min reaction time was chosen because we found that it was consistently sufficient to recover $>85 \%$ of AHL after $24 \mathrm{~h}$ reactions (Figure S3). The AHL measured in the latter fraction represents the sum of the AHL and Acyl-HS at the end of each reaction, that is, $[\mathrm{AHL}]_{\text {soluble }}+[$ AcylHS $]_{\text {soluble. }}$ The fraction of nonhydrolyzed AHL at each time point was calculated by dividing the GC-MS signal obtained from the untreated sample by the signal obtained with the acidtreated sample.

Gas Chromatography-Mass Spectrometry. We measured the rate of lactone hydrolysis using GC-MS. The chloroform extractions were transferred to $2 \mathrm{~mL}$ amber vials and analyzed using an Agilent 6890 gas chromatograph equipped with a capillary column $(30 \mathrm{~m} \times 250 \mu \mathrm{m}$ ID and $0.25 \mu \mathrm{m}$ film thickness) coated with $5 \% \mathrm{Ph}$ Me siloxane in selective ion monitoring mode. ${ }^{36}$ We injected each sample at splitless mode using $\mathrm{He}$ as a carrier gas. The injector temperature was set at $200{ }^{\circ} \mathrm{C}$, and the oven was set to hold at $150{ }^{\circ} \mathrm{C}$ for $1 \mathrm{~min}$, and then to increase by $20{ }^{\circ} \mathrm{C} \min ^{-1}$ to $230{ }^{\circ} \mathrm{C}, 10{ }^{\circ} \mathrm{C} \mathrm{min}^{-1}$ from 230 to $260{ }^{\circ} \mathrm{C}$, and $20{ }^{\circ} \mathrm{C} \mathrm{min}{ }^{-1}$ from 260 to $300{ }^{\circ} \mathrm{C}$. We used a solvent delay $(3 \mathrm{~min})$ to prevent interference from the extraction solvent.

Accumulation of Acyl-HS. To establish whether Acyl-HS accumulates in the aqueous phase after exposing AHL to charcoals, oilseed rape and mixed softwood $550^{\circ} \mathrm{C}$ charcoals $(5$ $\mathrm{mg} / \mathrm{mL})$ were placed in petri dishes $(60 \times 15 \mathrm{~mm})$ containing $2 \mu \mathrm{M}$ AHL and $5 \mathrm{~mL}$ water. After $1 \mathrm{~h}$ at $23^{\circ} \mathrm{C}$ while shaking at $50 \mathrm{rpm}$, the liquid in the petri dishes was transferred to a sterile $2 \mathrm{~mL}$ eppendorf tube, and centrifugation was used to remove the charcoal. One supernatant fraction was used to measure the $\mathrm{pH}$, a second fraction was analyzed using our microbial bioassay to determine the AHL concentrations, and a third fraction was acidified to $\mathrm{pH}<3$ using $\mathrm{HCl}$ and reacted for 90 and $135 \mathrm{~min}$ before analysis for AHL content. In each experiment, AHL concentration was measured using serial dilutions $(1,5,25,125$, and $625 \times$ ) of the acidified and untreated fractions. To calculate the AHL concentration, we compared the signal from each experiment with the signal in a standard curve generated by growing cells in the presence of different AHL concentrations and fitting the data to the Michaelis-Menten equation. The two dilutions that yielded signals within the most sensitive range of the microbial assay $(0.4-40 \mathrm{nM})$ were used to calculate the AHL concentrations. This approach minimized errors in estimates by avoiding GFP signals that were too near saturation or background.
Modeling. The model consisted of five first-order ordinary differential equations that described the time-dependent concentrations of the different molecular species that can arise: (i) aqueous soluble AHL [AHL], (ii) aqueous soluble Acyl-HS [HS], (iii) insoluble charcoal-bound [AHL-BC], (iv) insoluble charcoal-bound Acyl-HS [HS-BC], and (v) charcoal binding sites for AHL and Acyl-HS [BC]. The time-dependent AHL and Acyl-HS concentrations are described by

$$
\begin{aligned}
\mathrm{d}[\mathrm{AHL}] / \mathrm{d} t= & -\left(k_{\mathrm{hyd} 1}\left[\mathrm{OH}^{-}\right]+k_{\mathrm{hyd} 2}\right)[\mathrm{AHL}] \\
& +\left(k_{\mathrm{dehyd} 1}\left[\mathrm{H}^{+}\right]+k_{\mathrm{dehyd} 2}\right)[\mathrm{HS}] \\
& -k_{\mathrm{s}}[\mathrm{AHL}][\mathrm{BC}] \\
\mathrm{d}[\mathrm{HS}] / \mathrm{d} t= & \left(k_{\mathrm{hyd} 1}\left[\mathrm{OH}^{-}\right]+k_{\mathrm{hyd} 2}\right)[\mathrm{AHL}] \\
& -\left(k_{\mathrm{dehyd} 1}\left[\mathrm{H}^{+}\right]+k_{\mathrm{dehyd} 2}\right)[\mathrm{HS}] \\
& -k_{\mathrm{s}}[\text { Acyl-HS }][\mathrm{BC}]
\end{aligned}
$$

In this model, $k_{\text {hyd } 1}$ and $k_{\text {hyd2 }}$ represent the hydroxidedependent and hydroxide-independent rates of hydrolysis, respectively. ${ }^{37}$ The dehydration of Acyl-HS is described with the hydrogen-ion-dependent term $k_{\text {dehyd1 }}$ and the independent term $k_{\text {dehyd2 }}$. Because of the chemical and structural similarities between AHL and Acyl-HS, their rates of association with charcoal were represented by a single rate constant, $k_{\mathrm{s}}$. This binding reaction was assumed to be irreversible. The concentrations of the charcoal-bound AHL [AHL-BC] and Acyl-HS [HS-BC] are described by eqs 3 and 4

$$
\begin{aligned}
& \mathrm{d}[\mathrm{AHL}-\mathrm{BC}] / \mathrm{d} t=k_{\mathrm{s}}[\mathrm{AHL}][\mathrm{BC}] \\
& \mathrm{d}[\mathrm{HS}-\mathrm{BC}] / \mathrm{d} t=k_{\mathrm{s}}[\mathrm{HS}][\mathrm{BC}]
\end{aligned}
$$

The concentration of the charcoal binding sites [BC] is described by eq 5

$$
\mathrm{d}[\mathrm{BC}] / \mathrm{d} t=-k_{\mathrm{s}}([\mathrm{AHL}]+[\mathrm{HS}])[\mathrm{BC}]
$$

We obtained the rate constants for AHL hydrolysis $\left(k_{\mathrm{hyd} 1}\right.$, $\left.k_{\text {hyd2 } 2}\right)$ and Acyl-HS dehydration $\left(k_{\text {dehyd } 1}\right.$ and $\left.k_{\text {dehyd2 } 2}\right)$ by globally fitting our kinetic AHL hydrolysis data from GC-MS analysis (Figure S4) to this model; $k_{\mathrm{s}}$ was estimated by fitting the model to the results of the microbial assay. The AHL half-life was calculated by fitting the time-dependent [AHL] for each SA and $\mathrm{pH}$ combination to the exponential decay equation (eq 6)

$$
[\mathrm{AHL}]=[\mathrm{AHL}]_{t=0} \times 2^{\left(-t / t_{1 / 2}\right)}
$$

where $[\mathrm{AHL}]_{t=0}$ is the initial concentration and $t_{1 / 2}$ represents its half-life. The model predictions were generated using a defined range of SA $\left(0.01-7.2 \mathrm{~m}^{2} \mathrm{~mL}^{-1}\right)$ and $\mathrm{pH}(6.25-10.5)$ values.

\section{RESULTS AND DISCUSSION}

Charcoal Effects on AHL and $\mathrm{pH}$. Prior studies have reported that alkaline conditions accelerate hydrolysis of the AHL lactone ring, ${ }^{21,22}$ suggesting that some alkaline charcoals may destabilize these cell-cell signaling molecules through hydrolysis. To test this idea, we examined the relationship between charcoal-induced $\mathrm{pH}$ changes and the bioavailable level of AHL after $1 \mathrm{~h}$ of exposure to charcoal. For this analysis, we measured the $\mathrm{pH}$ of the charcoal-treated AHL solutions at the end of each exposure and the ability of the solutions to induce a GFP signal in a microbial assay. In all cases, we found 


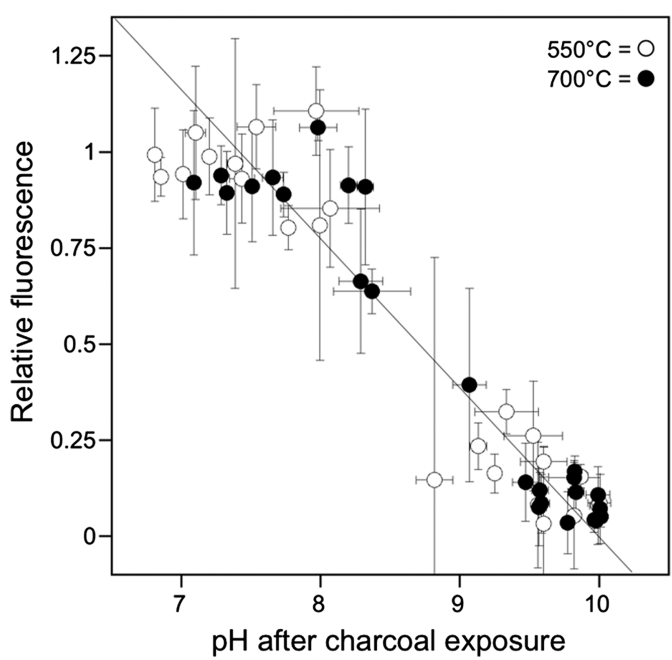

Figure 1. Charcoal-induced $\mathrm{pH}$ increases are inversely correlated with bioavailable AHL. The relative fluorescence of E. coli mixed with charcoal-treated $\mathrm{AHL}$ is compared with the $\mathrm{pH}$ value after exposure to $1,5,10,25$, and $50 \mathrm{mg} / \mathrm{mL}$ of wheat straw, oilseed rape, softwood, miscanthus straw, and rice husk charcoals for $1 \mathrm{~h}$. The measurements were performed using $550{ }^{\circ} \mathrm{C}$ (open symbols) and $700{ }^{\circ} \mathrm{C}$ (closed symbols) charcoals in triplicate and are reported as mean $\pm 1 \sigma . R=$ 0.95 was obtained from a linear fit $(y=9.9865-2.5809 x)$ to the data.

that increasing the charcoal concentrations led to an elevated $\mathrm{pH}$ (Figure S5). To determine how $\mathrm{pH}$ relates to quenching of the AHL-dependent GFP signal across different feedstocks, we compared the $\mathrm{pH}$ and GFP signal from each experiment (Figure 1). Below $\mathrm{pH} 8$, the GFP signal was similar to that observed in the absence of charcoals, whereas the GFP signal decreased above $\mathrm{pH} 8$. A linear fit to the data acquired using all of the charcoals yielded a strong correlation coefficient $(R=$ 0.95) for the inverse relationship between the charcoal $\mathrm{pH}$ and the GFP signal. Strong linear correlations were also obtained when we analyzed the charcoals from each pyrolysis temperature separately (Figure S6).
The inverse correlation between the charcoal $\mathrm{pH}$ and the GFP signal suggested that the AHL hydrolysis might at times account for a significant fraction of the decrease in the bioavailable AHL. To evaluate the relative contributions of AHL surface sorption and hydrolysis under the conditions of our experiment, we tested the ability of our biosensor to detect AHL after the AHL had been exposed to acidified charcoal. Because the AHL hydrolysis rate becomes significant above $\mathrm{pH}$ 7 , $^{22}$ we investigated whether charcoals have smaller effects on bioavailable AHL when adjusted to a lower $\mathrm{pH}$ value. For this experiment, we analyzed the effect of $\mathrm{pH}$-adjusted and untreated miscanthus straw charcoal $\left(550{ }^{\circ} \mathrm{C}\right)$ on the GFP signal in our bioassay. We found that the miscanthus straw charcoal had a very strong buffer capacity, presenting elevated $\mathrm{pH}$ values even after initial $\mathrm{pH}$ adjustment (Figure 2). The acid-treated miscanthus straw charcoal had $\mathrm{pH}$ values that ranged from 4 to 7 , whereas the untreated miscanthus straw charcoal ranged from 6 to 10 . Without $\mathrm{pH}$ adjustment, treatment of an AHL solution with $10 \mathrm{mg} / \mathrm{mL}$ charcoal decreased the GFP signal to a half-maximal value and yielded a $\mathrm{pH}$ of $\sim 9$. In contrast, with $\mathrm{pH}$ adjustment, the GFP signal only decreased by $\sim 20 \%$ at the highest charcoal concentration analyzed, that is, $50 \mathrm{mg} / \mathrm{mL}$. This charcoal-treated solution had a near-neutral $\mathrm{pH}$. These results suggest that the large decrease in bioavailable AHL observed with the untreated miscanthus straw charcoal arises to a large extent because the charcoalinduced $\mathrm{pH}$ changes accelerate AHL hydrolysis. The smaller loss of bioavailable AHL with the acidified charcoal is interpreted as arising from sorption because this analysis was performed under $\mathrm{pH}$ conditions that are not predicted to hydrolyze AHL.

Our experiments suggested that charcoals decrease the bioavailable AHL on the time course of our experiments through two mechanisms. As previously suggested, charcoals decrease the bioavailable concentration of AHL through sorption. In addition, charcoals convert biologically active AHL into soluble Acyl-HS, which is no longer biologically active. To directly investigate whether AHL is converted into Acyl-HS before charcoal sorption as predicted from the second
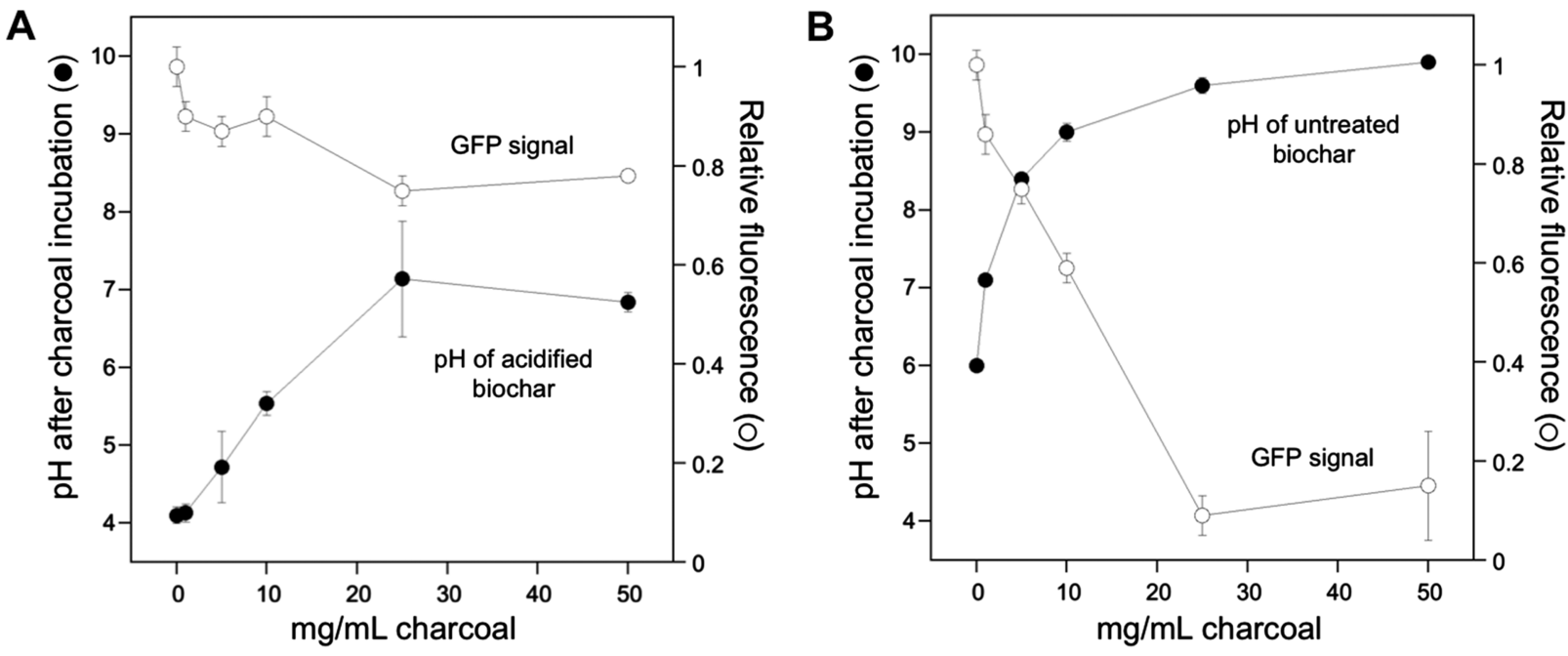

Figure 2. Charcoal acidification increases bioavailable AHL. (A) Varying concentrations of $550{ }^{\circ} \mathrm{C}$ miscanthus straw charcoal were acidified to $\mathrm{pH} 3$ and exposed to AHL. After $1 \mathrm{~h}$, the $\mathrm{pH}$ and the level of GFP expression induced by AHL remaining in the solution were measured. (B) Effects of untreated miscanthus straw charcoal $\left(550^{\circ} \mathrm{C}\right)$ on GFP expression and $\mathrm{pH}$. The error bars represent $\pm 1 \sigma$ calculated using three independent measurements. 
A

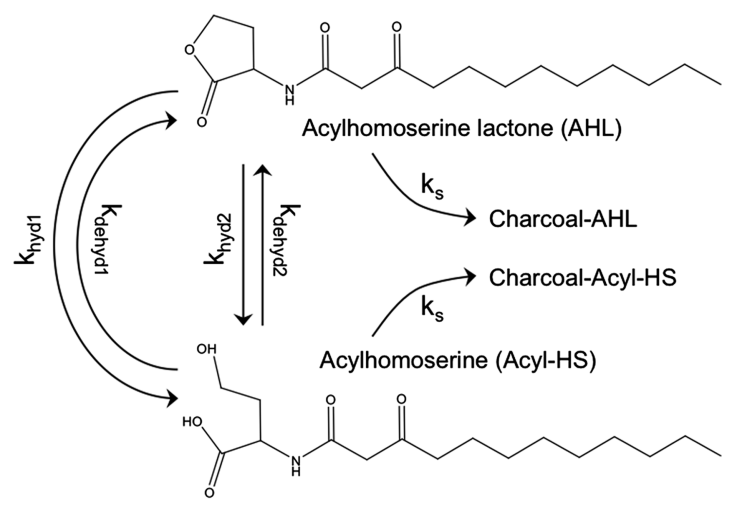

B

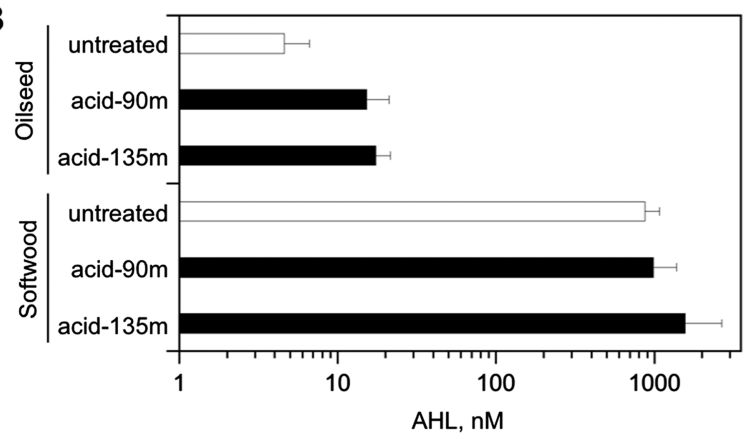

Figure 3. Charcoals can convert AHL into soluble Acyl-HS before sorption. (A) AHL can be inactivated through $\mathrm{pH}$-dependent hydrolysis $\left(k_{\text {hyd } 1}\right), \mathrm{pH}$-independent hydrolysis $\left(k_{\text {hyd2 } 2}\right)$, and sorption to charcoal $\left(k_{\mathrm{s}}\right)$. AHL can also be generated by dehydrating Acyl-HS $\left(k_{\text {dehyd } 1}\right.$ and $\left.k_{\text {dehyd2 } 2}\right)$. (B) Oilseed rape and softwood $550{ }^{\circ} \mathrm{C}$ charcoals were reacted with AHL for $1 \mathrm{~h}$, and the fraction of soluble AHL was measured (untreated) as well as the total concentration of AHL and Acyl-HS. The latter was quantified by acidifying the samples for 90 and $135 \mathrm{~min}$ (acid-90m and acid-135m) before analyzing the AHL levels. The AHL in the acidified samples from the oilseed rape reactions was significantly higher than in the untreated fraction (two-tailed $t$-test; $p<$ 0.01 ), whereas no significant difference was observed between the untreated and acidified samples from softwood. The error bars represent $\pm 1 \sigma$ calculated using three independent measurements.

mechanism (Figure 3A), we exposed low- and high-pH charcoals to AHL for $1 \mathrm{~h}$, split the aqueous portion of each sample, acidified one fraction while leaving the other sample untreated, and measured the concentration of bioavailable AHL in each sample. When this analysis was performed with the oilseed rape $550{ }^{\circ} \mathrm{C}$ charcoal, one of the more-alkaline charcoals, the acid-treated fractions yielded AHL concentrations that were significantly higher than those observed in the untreated fraction (Figure 3B). Because acidic conditions promote the dehydration of Acyl-HS back to AHL, the increased yield of AHL with acid-treated fractions provides evidence for Acyl-HS accumulation in the presence of this charcoal. When this analysis was performed with the charcoal having the lowest $\mathrm{pH}$ (softwood $550{ }^{\circ} \mathrm{C}$ ), the acid-treated fractions yielded AHL concentrations that were not significantly different from the untreated fraction. Together, these results lead us to conclude that charcoal alkalinity contributes to the loss of AHL by hydrolyzing this signaling chemical.

Modeling Charcoal Effects on AHL. To predict how charcoals with different SAs and alkalinities affect AHL concentrations, we built a kinetic model that reports how AHL levels change with time upon exposure to charcoals having different physicochemical properties. In this model, the concentration of biologically available AHL depends upon $\mathrm{pH}$ dependent and $\mathrm{pH}$-independent AHL hydrolysis reactions $\left(k_{\text {hyd1 }}\right.$ and $\left.k_{\text {hyd } 2}\right), \mathrm{pH}-$ dependent and $\mathrm{pH}$-independent Acyl-HS dehydrations reactions $\left(k_{\text {dehyd1 }}\right.$ and $\left.k_{\text {dehyd2 }}\right)$, and AHL and AcylHS sorption reactions $\left(k_{\mathrm{s}}\right)$. Our model also considers the concentrations of soluble [AHL] and [Acyl-HS], $\mathrm{pH}$, and the charcoal SA. The rate constants describing the hydrolysis and dehydration reactions were obtained by globally fitting the kinetics of AHL hydrolysis to our model (Figure S4).

As a frame of reference for our model, we analyzed the relative influence of $\mathrm{pH}$ and $\mathrm{SA}$ of the UKBRC charcoals on the AHL-dependent GFP signal in our microbial assay (Figure $\mathrm{S} 7 \mathrm{~A})$. At the $1 \mathrm{~h}$ time point when we performed our measurements, the GFP signal displayed a stronger correlation with $\mathrm{pH}$ compared with SA. When we fit our kinetic model to the data from this time point, using kinetic values for hydrolysis and dehydration measured in the absence of charcoal, we obtained a sorption rate constant $k_{\mathrm{s}}=0.0039 \mathrm{~h}^{-1} \mathrm{mM}^{-1}$ that allowed us to estimate the effects of charcoals on AHL activity over a greater set of $\mathrm{pH}$ and SA values (Figure S7B). We used our model with this $k_{\mathrm{s}}$ value to calculate the time-dependent changes in AHL over the same range of physicochemical charcoal parameters (Figure 4A). This analysis revealed that the AHL half-life varies up to 5620 times across the different $\mathrm{pH}$ and SA values analyzed (Figure 4B). For these calculations, we used charcoal SAs that overlap with the range that has been used for soil amendment. ${ }^{3}$ A smaller half-life range (273-fold) was observed when calculations were performed with farnesol (Figure 4C), a fungal autoinducer that lacks the $\mathrm{pH}$-sensitive lactone found in AHLs. ${ }^{38}$

Environmental Implications. Our results provide evidence that charcoals can decrease the concentrations of autoinducers used for cell-cell signaling through multiple chemical mechanisms, including sorption and hydrolysis. Because these reactions occur through distinct mechanisms, their rates are controlled by distinct physicochemical properties of charcoals. With sorption, the charcoal SA will control AHL sorption as observed with apolar chemicals. ${ }^{25-28}$ In contrast, hydrolysis is predicted to depend upon charcoal alkalinity, which varies with feedstock and pyrolysis conditions, ${ }^{30,31}$ and does not always correlate with SA. Microbes will likely respond to charcoal-induced AHL depletion, and this response will depend on the soil type, ecosystem conditions, and charcoal amendment rate. Some soils may buffer the $\mathrm{pH}$ effects arising from charcoal addition, particularly those soils rich in organic matter and metal oxides (iron and aluminum) that have a strong buffering capacity. ${ }^{39}$ In these soils, our results predict that charcoals will quench AHL signaling primarily through sorption. In soils having limited buffering capacities, charcoals will quench AHL signaling through both hydrolysis and sorption. The AHL concentrations observed in a given environment may be influenced by the presence of lactonases, enzymes synthesized by soil microbes that catalyze AHL hydrolysis. ${ }^{19}$ Whether or not the activity of these enzymes is modulated by charcoal addition is not known.

The relative contributions that sorption and hydrolysis make to charcoal quenching of microbial communication are expected to vary across species because of the structural and chemical diversity in signaling molecules. ${ }^{23}$ Our findings suggest that within a single soil, the rates of charcoal quenching of different cell-cell communication reactions will vary. We expect charcoal to sorb (and quench) all types of signaling compounds used for cell-cell communication as previously 
A

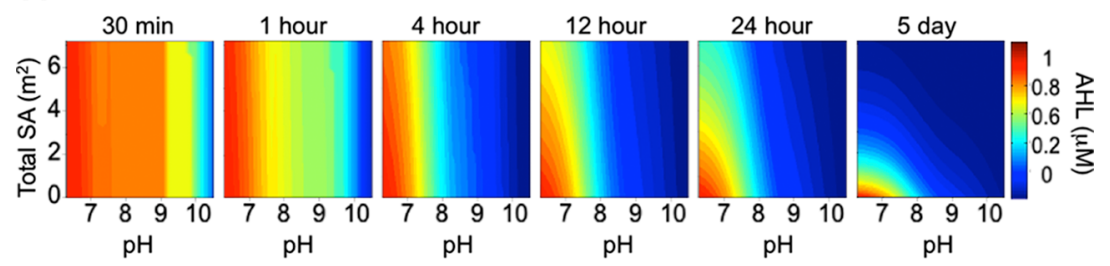

B

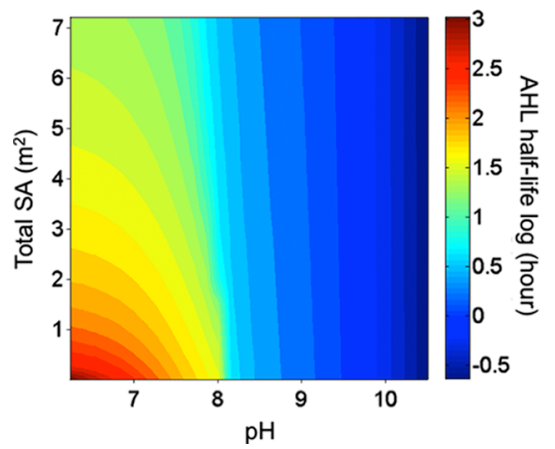

C

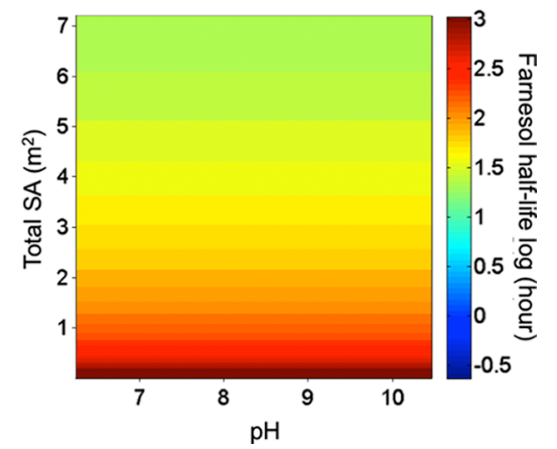

Figure 4. Modeling the effect of charcoals on AHL availability. The kinetic model suggested that the charcoal pH has a more immediate effect on the half-life of AHL compared with charcoal SA. (A) AHL concentration changes over time with different physiochemical charcoal parameters. The color gradient represents the AHL remaining after mixing with charcoal. The calculated half-lives of (B) AHL and (C) farnesol when reacted with charcoals having a range of SA and $\mathrm{pH}$ values. The colors represent the logarithm of the calculated half-lives in hours.

proposed, ${ }^{11}$ although the extent and rate of sorption may vary with signaling molecule structure. However, only a subset of signaling compounds will be hydrolyzed by the charcoal-driven $\mathrm{pH}$ shifts. In the case of farnesol, a fungal autoinducer, ${ }^{40}$ we predict sorption to be the dominant mechanism by which charcoal could decrease the bioavailable concentration because this chemical does not contain functional groups whose stability varies with $\mathrm{pH}$ like AHL. However, other classes of signals may be sensitive to charcoal-induced $\mathrm{pH}$ changes like AHL. For example, oligopeptide autoinducers display a charge that depends upon soil $\mathrm{pH}$ because they contain functional groups whose protonation can change. ${ }^{23}$ This protonation is not expected to promote hydrolysis as observed with AHL but could alter charcoal sorption by changing the oligopeptide charge and altering the ionic interactions as observed with other chemicals whose protonation changes with $\mathrm{pH}^{41}$

Our modeling results suggest that the complex biological effects of charcoal in the environment, such as changes in microbial community structure, ${ }^{42,43}$ could arise because charcoals differentially affect microbial species by altering cell-cell signaling that enhances or inhibits growth. Indeed, both inhibitory and stimulatory effects on microbial physiological activities and population induced by charcoal have been reported. In one incubation study, the biomass of Gramnegative bacteria was significantly increased as a result of soil charcoal addition, whereas fungal and Gram-positive bacterial biomasses were less affected. ${ }^{1}$ In another field study, charcoal increased both bacterial and fungal populations. However, in this case, charcoal shifted the microbial community toward a greater relative amount of bacteria. ${ }^{2}$ In both studies, no clear mechanism was established for the charcoal-mediated microbial responses. Additional research is needed to establish how charcoal quenching of cell-cell communication relates to dynamic community-level changes in situ. The recent development of biosensors that provide dynamic information on gene expression in a soil should aid in future studies examining charcoal effects on cell-cell signaling. ${ }^{44}$

\section{ASSOCIATED CONTENT}

\section{Supporting Information}

The Supporting Information is available free of charge on the ACS Publications website at DOI: 10.1021/acsomega.6b00085.

The physical and chemical characterization of charcoals, the effects of charcoals on AHL-dependent GFP expression, the recovery of AHL using acidification, the effect of $\mathrm{pH}$ on AHL hydrolysis, the relationship between charcoal concentration and $\mathrm{pH}$ changes, the relationship between charcoal alkalinity and AHL-dependent GFP expression, and kinetic model results (PDF)

\section{AUTHOR INFORMATION}

\section{Corresponding Author}

*E-mail: joff@rice.edu. Phone: 713-348-3849.

\section{Author Contributions}

${ }^{\perp}$ X.G. and H.-Y.C. contributed equally to this work.

\section{Notes}

The authors declare no competing financial interest.

\section{ACKNOWLEDGMENTS}

We are grateful for financial support from the Keck Foundation (to C.A.M. and J.J.S.), the Rice Faculty Initiative Fund (to C.A.M. and J.J.S.), Royal Dutch Shell Oil (to C.A.M. and J.J.S.), and the Taiwan Ministry of Education Scholarship (to H.-Y.C.). We appreciate conversations with and the support of J. Wise.

\section{REFERENCES}

(1) Watzinger, A.; Feichtmair, S.; Kitzler, B.; Zehetner, F.; Kloss, S.; Wimmer, B.; Zechmeister-Boltenstern, S.; Soja, G. Soil microbial communities responded to biochar application in temperate soils and slowly metabolized ${ }^{13} \mathrm{C}$-labelled biochar as revealed by ${ }^{13} \mathrm{C}$ PLFA analyses: results from a short-term incubation and pot experiment. Eur. J. Soil Sci. 2013, 65, 40-51. 
(2) Ippolito, J. A.; Stromberger, M. E. Hardwood biochar influences calcareous soil physicochemical and microbiological status. J. Environ. Qual. 2014, 43, 681-689.

(3) Rondon, M. A.; Lehmann, J.; Ramírez, J.; Hurtado, M. Biological nitrogen fixation by common beans (Phaseolus vulgaris L.) increases with bio-char additions. Biol. Fertil. Soils 2006, 43, 699-708.

(4) Güereña, D. T.; Lehmann, J.; Thies, J. E.; Enders, A.; Karanja, N.; Neufeldt, H. Partitioning the contributions of biochar properties to enhanced biological nitrogen fixation in common bean (Phaseolus vulgaris). Biol. Fertil. Soils 2015, 51, 479-491.

(5) LeCroy, C.; Masiello, C. A.; Rudgers, J. A.; Hockaday, W. C.; Silberg, J. J. Nitrogen, biochar, and mycorrhizae: Alteration of the symbiosis and oxidation of the char surface. Soil Biol. Biochem. 2013, $58,248-254$.

(6) Robertson, S. J.; Rutherford, P. M.; López-Gutiérrez, J. C.; Massicotte, H. B. Biochar enhances seedling growth and alters root symbioses and properties of sub-boreal forest soils. Can. J. Soil Sci. 2012, 92, 329-340.

(7) Wardle, D. A.; Nilsson, M.-C.; Zackrisson, O. Fire-derived charcoal causes loss of forest humus. Science 2008, 320, 629.

(8) Zimmerman, A. R.; Gao, B.; Ahn, M.-Y. Positive and negative carbon mineralization priming effects among a variety of biocharamended soils. Soil Biol. Biochem. 2011, 43, 1169-1179.

(9) Whitman, T.; Zhu, Z.; Lehmann, J. Carbon mineralizability determines interactive effects on mineralization of pyrogenic organic matter and soil organic carbon. Environ. Sci. Technol. 2014, 48, 1372713734.

(10) Warnock, D. D.; Lehmann, J.; Kuyper, T. W.; Rillig, M. C. Mycorrhizal responses to biochar in soil-concepts and mechanisms. Plant Soil 2007, 300, 9-20.

(11) Masiello, C. A.; Chen, Y.; Gao, X.; Liu, S.; Cheng, H.-Y.; Bennett, M. R.; Rudgers, J. A.; Wagner, D. S.; Zygourakis, K.; Silberg, J. J. Biochar and Microbial Signaling: Production Conditions Determine Effects on Microbial Communication. Environ. Sci. Technol. 2013, 47, 11496-11503.

(12) Miller, M. B.; Bassler, B. L. Quorum sensing in bacteria. Annu. Rev. Microbiol. 2001, 55, 165-199.

(13) González, J. E.; Marketon, M. M. Quorum sensing in nitrogenfixing rhizobia. Microbiol. Mol. Biol. Rev. 2003, 67, 574-592.

(14) Paspaliari, D. K.; Mollerup, M. S.; Kallipolitis, B. H.; Ingmer, H.; Larsen, M. H. Chitinase expression in Listeria monocytogenes is positively regulated by the Agr system. PLoS One 2014, 9, No. e95385. (15) Zhang, G.; Zhang, F.; Ding, G.; Li, J.; Guo, X.; Zhu, J.; Zhou, L.; Cai, S.; Liu, X.; Luo, Y.; et al. Acyl homoserine lactone-based quorum sensing in a methanogenic archaeon. ISME J. 2012, 6, 1336-1344.

(16) Batchelor, S. E.; Cooper, M.; Chhabra, S. R.; Glover, L. A.; Stewart, G. S.; Williams, P.; Prosser, J. I. Cell density-regulated recovery of starved biofilm populations of ammonia-oxidizing bacteria. Appl. Environ. Microbiol. 1997, 63, 2281-2286.

(17) Toyofuku, M.; Nomura, N.; Fujii, T.; Takaya, N.; Maseda, H.; Sawada, I.; Nakajima, T.; Uchiyama, H. Quorum sensing regulates denitrification in Pseudomonas aeruginosa PAO1. J. Bacteriol. 2007, 189, 4969-4972.

(18) Toyofuku, M.; Nomura, N.; Kuno, E.; Tashiro, Y.; Nakajima, T.; Uchiyama, H. Influence of the Pseudomonas quinolone signal on denitrification in Pseudomonas aeruginosa. J. Bacteriol. 2008, 190, 7947-7956.

(19) Dong, Y.-H.; Wang, L.-H.; Xu, J.-L.; Zhang, H.-B.; Zhang, X.-F.; Zhang, L.-H. Quenching quorum-sensing-dependent bacterial infection by an $\mathrm{N}$-acyl homoserine lactonase. Nature 2001, 411, 813817.

(20) Arunkumar, M.; Suhashini, K.; Mahesh, N.; Ravikumar, R. Quorum quenching and antibacterial activity of silver nanoparticles synthesized from Sargassum polyphyllum. Bangladesh J. Pharmacol. 2014, 9, 54-59.

(21) Byers, J. T.; Lucas, C.; Salmond, G. P. C.; Welch, M. Nonenzymatic Turnover of an Erwinia carotovora Quorum-Sensing Signaling Molecule. J. Bacteriol. 2002, 184, 1163-1171.
(22) Yates, E. A.; Philipp, B.; Buckley, C.; Atkinson, S.; Chhabra, S. R.; Sockett, R. E.; Goldner, M.; Dessaux, Y.; Camara, M.; Smith, H.; et al. N-Acylhomoserine Lactones Undergo Lactonolysis in a $\mathrm{pH}$-, Temperature-, and Acyl Chain Length-Dependent Manner during Growth of Yersinia pseudotuberculosis and Pseudomonas aeruginosa. Infect. Immun. 2002, 70, 5635-5646.

(23) Grandclément, C.; Tannières, M.; Moréra, S.; Dessaux, Y.; Faure, D. Quorum quenching: Role in nature and applied developments. FEMS Microbiol. Rev. 2016, 40, 86-116.

(24) Lehmann, J.; Rillig, M. C.; Thies, J.; Masiello, C. A.; Hockaday, W. C.; Crowley, D. Biochar effects on soil biota-A review. Soil Biol. Biochem. 2011, 43, 1812-1836.

(25) Kasozi, G. N.; Zimmerman, A. R.; Nkedi-Kizza, P.; Gao, B. Catechol and Humic Acid Sorption onto a Range of LaboratoryProduced Black Carbons (Biochars). Environ. Sci. Technol. 2010, 44, 6189-6195

(26) Cao, X.; Ma, L.; Liang, Y.; Gao, B.; Harris, W. Simultaneous Immobilization of Lead and Atrazine in Contaminated Soils Using Dairy-Manure Biochar. Environ. Sci. Technol. 2011, 45, 4884-4889.

(27) Hale, S.; Hanley, K.; Lehmann, J.; Zimmerman, A.; Cornelissen, G. Effects of Chemical, Biological, and Physical Aging As Well As Soil Addition on the Sorption of Pyrene to Activated Carbon and Biochar. Environ. Sci. Technol. 2011, 45, 10445-10453.

(28) Tang, J.; Lv, H.; Gong, Y.; Huang, Y. Preparation and characterization of a novel graphene/biochar composite for aqueous phenanthrene and mercury removal. Bioresour. Technol. 2015, 196, $355-363$.

(29) Kinney, T. J.; Masiello, C. A.; Dugan, B.; Hockaday, W. C.; Dean, M. R.; Zygourakis, K.; Barnes, R. T. Hydrologic properties of biochars produced at different temperatures. Biomass Bioenergy 2012, 41, 34-43.

(30) Kloss, S.; Zehetner, F.; Dellantonio, A.; Hamid, R.; Ottner, F.; Liedtke, V.; Schwanninger, M.; Gerzabek, M. H.; Soja, G. Characterization of Slow Pyrolysis Biochars: Effects of Feedstocks and Pyrolysis Temperature on Biochar Properties. J. Environ. Qual. 2012, 41, 990.

(31) Wu, W.; Yang, M.; Feng, Q.; McGrouther, K.; Wang, H.; Lu, H.; Chen, Y. Chemical characterization of rice straw-derived biochar for soil amendment. Biomass Bioenergy 2012, 47, 268-276.

(32) Wiedemeier, D. B.; Abiven, S.; Hockaday, W. C.; Keiluweit, M.; Kleber, M.; Masiello, C. A.; McBeath, A. V.; Nico, P. S.; Pyle, L. A.; Schneider, M. P. W.; et al. Aromaticity and degree of aromatic condensation of char. Org. Geochem. 2015, 78, 135-143.

(33) Spokas, K. A.; Reicosky, D. C. Impacts of Sixteen Different Biochars on Soil Greenhouse Gas Production. Ann. Environ. Sci. 2009, 3, 179-193.

(34) Burton, E. O.; Read, H. W.; Pellitteri, M. C.; Hickey, W. J. Identification of acyl-homoserine lactone signal molecules produced by Nitrosomonas europaea strain Schmidt. Appl. Environ. Microbiol. 2005, 71, 4906-4909.

(35) Morin, D.; Grasland, B.; Vallée-Réhel, K.; Dufau, C.; Haras, D. On-line high-performance liquid chromatography-mass spectrometric detection and quantification of $\mathrm{N}$-acylhomoserine lactones, quorum sensing signal molecules, in the presence of biological matrices. J. Chromatogr. A 2003, 1002, 79-92.

(36) Cataldi, T.; Bianco, G.; Palazzo, L.; Quaranta, V. Occurrence of $\mathrm{N}$-acyl-L-homoserine lactones in extracts of some Gram-negative bacteria evaluated by gas chromatography-mass spectrometry. Anal. Biochem. 2007, 361, 226-235.

(37) Fassberg, J.; Stella, V. J. A Kinetic and Mechanistic Study of the Hydrolysis of Camptothecin and Some Analogues. J. Pharm. Sci. 1992, $81,676-684$.

(38) Nickerson, K. W.; Atkin, A. L.; Hornby, J. M. Quorum sensing in dimorphic fungi: Farnesol and beyond. Appl. Environ. Microbiol. 2006, 72, 3805-3813.

(39) Curtin, D.; Trolove, S. Predicting pH buffering capacity of New Zealand soils from organic matter content and mineral characteristics. Soil Res. 2013, 51, 494-502.

(40) Hornby, J. M.; Jensen, E. C.; Lisec, A. D.; Tasto, J. J.; Jahnke, B.; Shoemaker, R.; Dussault, P.; Nickerson, K. W. Quorum sensing in the 
dimorphic fungus Candida albicans is mediated by farnesol. Appl. Environ. Microbiol. 2001, 67, 2982-2992.

(41) Essandoh, M.; Kunwar, B.; Pittman, C. U., Jr.; Mohan, D.; Mlsna, T. Sorptive removal of salicylic acid and ibuprofen from aqueous solutions using pine wood fast pyrolysis biochar. Chem. Eng. J. 2015, 265, 219-227.

(42) Whitman, T.; Pepe-Ranney, C.; Enders, A.; Koechli, C.; Campbell, A.; Buckley, D. H.; Lehmann, J. Dynamics of microbial community composition and soil organic carbon mineralization in soil following addition of pyrogenic and fresh organic matter. ISME J. 2016, DOI: 10.1038/ismej.2016.68.

(43) Noyce, G. L.; Winsborough, C.; Fulthorpe, R.; Basiliko, N. The microbiomes and metagenomes of forest biochars. Sci. Rep. 2016, 6, 26425.

(44) Cheng, H.-Y.; Masiello, C. A.; Bennett, G. N.; Silberg, J. J. Volatile Gas Production by Methyl Halide Transferase: An In Situ Reporter of Microbial Gene Expression In Soil. Environ. Sci. Technol. 2016, 50, 8750 . 